\title{
Endovascular Management of Aortoiliac Occlusive Disease
}

\author{
Melissa J. Neisen, M.D. ${ }^{1}$
}

\section{ABSTRACT}

Patients with aortoiliac occlusive disease (AIOD) may be asymptomatic or may have intermittent claudication or critical limb ischemia. Treatment options for AIOD include management of risk factors, endovascular intervention, and/or surgical revascularization.

KEYWORDS: Aortoiliac occlusive disease, peripheral arterial disease, intermittent claudication, critical limb ischemia, balloon angioplasty, stent, bypass graft

\begin{abstract}
Objectives: Upon completion of this article, the reader should be able to identify the diagnostic and therapeutic options available for aortoiliac occlusive disease.

Accreditation: Tufts University School of Medicine (TUSM) is accredited by the Accreditation Council for Continuing Medical Education to provide continuing medical education for physicians.

Credit: TUSM designates this educational activity for a maximum of 1 AMA PRA Category 1 Credit ${ }^{\mathrm{TM}}$. Physicians should only claim credit commensurate with the extent of their participation in the activity.
\end{abstract}

\section{CLINICAL PRESENTATION}

Peripheral arterial disease (PAD) affects 8 to 10 million people in the United States per year. ${ }^{1}$ One subset of PAD is aortoiliac occlusive disease (AIOD). AIOD can occur anywhere from the distal aorta to the common femoral arteries and is therefore called an "inflow lesion." Stenoses may be short- or long-segment, calcified, ulcerated, concentric or eccentric, single or multiple, unilateral or bilateral and may involve the aorta or iliac arteries alone or together. Focal infrarenal aortic stenoses that exclude the aortic bifurcation are fairly rare. This is most often seen in younger patients with less atherosclerotic disease. ${ }^{2}$ More commonly, distal aortic occlusive disease extends into the common iliac arteries. Hypoplastic aortoiliac syndrome is seen most commonly in female smokers, in which the atherosclerotic effects of smoking narrow an already small aorta and iliac arteries. The Rutherford and Fontaine scoring systems for PAD are compared in Table 1, and essentially divide patients with AIOD into those with no symptoms, intermittent claudication (IC), or critical limb ischemia (CLI). Asymptomatic patients with PAD would be unlikely to benefit from endovascular or surgical treatment and may experience treatment-related complications, and, therefore, intervention should be limited to those with lifestyle-limiting claudication or limb-threatening ischemia.

IC

IC of the lower extremity is classically muscular pain brought on by activity and relieved by short rest. The prevalence of IC is $3 \%$ in those less than 40 and $6 \%$ in those older than $60 .{ }^{1}$ Intermittent claudication caused by AIOD typically involves the thigh/buttock and may cause male impotence. Patients with IC should have lifestyle-limiting symptoms and be expected to have
${ }^{1}$ Minneapolis Vascular Physicians, Minneapolis Radiology Associates, Plymouth, Minnesota.

Address for correspondence and reprint requests: Melissa J. Neisen, M.D., Interventional Radiologist, Minneapolis Vascular Physicians, Minneapolis Radiology Associates, 2800 Campus Drive, Suite 20, Plymouth, MN 55441.
Peripheral Vascular Disease; Guest Editors, Robert A. Hieb, M.D., and Parag J. Patel, M.D.

Semin Intervent Radiol 2009;26:296-302. Copyright (C) 2009 by Thieme Medical Publishers, Inc., 333 Seventh Avenue, New York, NY 10001, USA. Tel: +1(212) 584-4662.

DOI 10.1055/s-0029-1242199. ISSN 0739-9529. 
Table 1 Fontaine's Stages and Rutherford's Categories

\begin{tabular}{|c|c|c|c|c|}
\hline \multicolumn{2}{|c|}{ Fontaine } & \multicolumn{3}{|c|}{ Rutherford } \\
\hline Stage & Clinical & Grade & Category & Clinical \\
\hline \multicolumn{5}{|c|}{ Claudication } \\
\hline I & Asymptomatic & 0 & 0 & Asymptomatic \\
\hline Ila & Mild claudication & I & 1 & Mild claudication \\
\hline \multirow[t]{2}{*}{$\mathrm{Ilb}$} & Moderate to severe claudication & । & 2 & Moderate claudication \\
\hline & & I & 3 & Severe claudication \\
\hline \multicolumn{5}{|c|}{ Critical limb ischemia } \\
\hline III & Ischemic rest pain & $\|$ & 4 & Ischemic rest pain \\
\hline \multirow[t]{2}{*}{ IV } & Ulceration or gangrene & III & 5 & Minor tissue loss \\
\hline & & III & 6 & Major tissue loss \\
\hline
\end{tabular}

reasonable symptom improvement from either endovascular or surgical revascularization prior to undergoing evaluation for revascularization. ${ }^{3}$ Of those patients who present with typical IC, after 5 years, 70 to $80 \%$ will have stable claudication, 10 to $20 \%$ will have worsening claudication, and 5 to $10 \%$ will develop CLI. ${ }^{1}$ Less

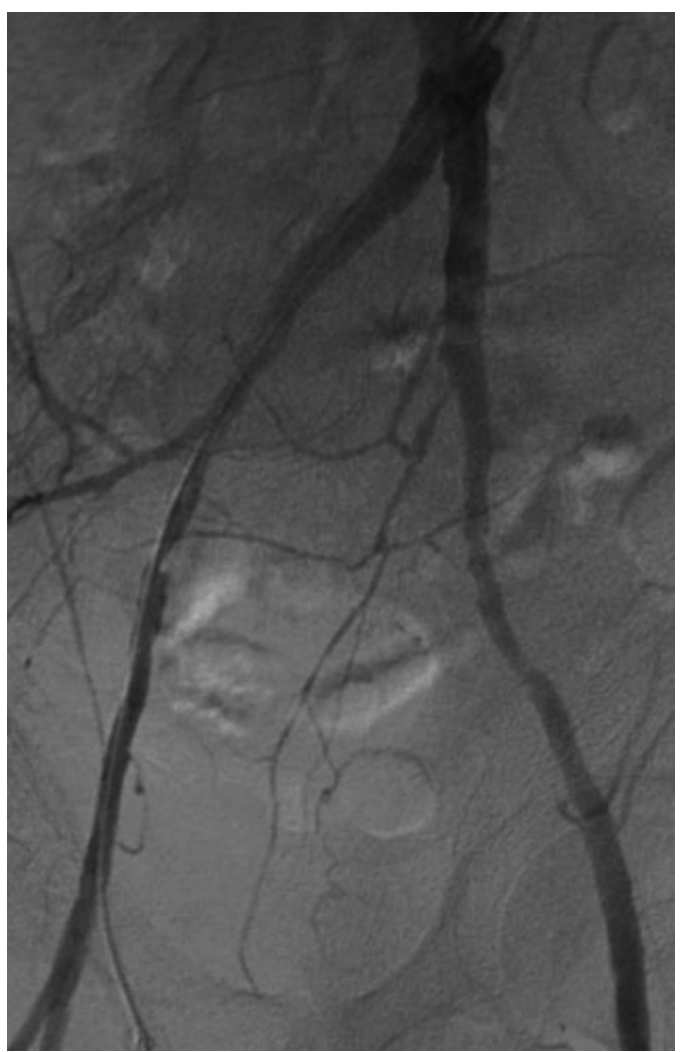

Figure 1 Changes of pelvic radiation for anal cancer. Pelvic oblique digital subtraction angiogram shows bilateral external iliac artery long-segment stenoses and left internal iliac artery origin stenosis. Patient was treated with primary stent placement in right external iliac artery and angioplasty with provisional stent placement in the left external iliac artery (not shown). than $2 \%$ of patients with IC go on to major amputation. ${ }^{4,5}$ Other causes of aortoiliac IC include arteritis, congenital and acquired coarctation of aorta, endofibrosis of the external iliac artery (EIA; iliac artery syndrome in cyclists), fibromuscular dysplasia, peripheral emboli, primary vascular tumors, pseudoxanthoma elasticum, remote trauma and radiation injury (Fig. 1), Takayasu's disease, thromboangiitis obliterans (Buerger's disease), and thrombosis of a persistent sciatic artery. ${ }^{1}$ Mimics for iliac artery IC include spinal stenosis and hip arthritis. Leriche syndrome is atheromatous occlusion of the distal abdominal aorta extending into the common iliac artery (CIA) origins with a triad of claudication, absent or weak femoral pulses, and erectile dysfunction.

\section{CLI}

CLI is defined as pain at rest and/or tissue loss. Of those with CLI, at 1 year $45 \%$ are alive with two lower extremities, 30\% undergo amputation, and 25\% have died. ${ }^{1}$ The differential diagnosis for rest pain includes diabetic neuropathy, complex regional pain syndrome, nerve root compression, and musculoskeletal disorders. In blue-toe syndrome, patients embolize distally, and this may occur even in the absence of claudication or significant stenosis. Symptoms must be present for more than 2 weeks to be considered chronic.

\section{PATHOGENESIS OF AIOD}

Risk factors for development of AIOD include nonwhite ethnicity, smoking, diabetes mellitus, dyslipidemia, hypertension, age, male gender, $\mathrm{C}$-reactive protein elevation, hyperhomocystinemia, hyperviscosity/hypercoagulability, and chronic renal insufficiency. ${ }^{1,6}$ Optimization of modifiable risk factors is an important component of successful management of patients with AIOD. 


\section{DIAGNOSIS}

\section{Noninvasive Methods}

The noninvasive methods for the evaluation for lowerextremity PAD include a focused history and physical examination, physiological ultrasound, computed tomographic angiography and magnetic resonance (MR) angiography. According to the American College of Cardiology (ACC)/American Heart Association (AHA) Guidelines for the Management of Patients with Peripheral Arterial Disease, ${ }^{3}$ individuals with risk factors for lower-extremity PAD should undergo a vascular review of systems to assess for claudication, rest pain, and/or wounds and should undergo a comprehensive pulse examination and foot inspection. Patients with CLI should undergo an expedited vascular evaluation. ${ }^{3}$ The Society of Interventional Radiology standard of practice regarding physiological evaluation of extremity arteries suggests the use of segmental blood pressures, continuous Doppler waveforms, and/or volume plethysmography to evaluate for PAD. ${ }^{7}$ Baseline bilateral ABI measurements should be obtained. An ankle brachial index (ABI) of $\leq 0.90$ is indicative of PAD. An exercise ABI may be useful for those with or without IC who have a normal resting $\mathrm{ABI}$, and measurement of toe-brachial index or pulse volume recording may be useful in asymptomatic $\mathrm{pa}^{-}$ tients if the resting $\mathrm{ABI}$ is greater than $1.30 .^{3}$ Color flow duplex ultrasonography may also be helpful to characterize stenoses, although in the aortoiliac system, this may be difficult based on patient body habitus. Computed tomographic angiography may be used to localize and diagnose severity of stenoses in individuals with PAD, especially in those with a contraindication to MR angiography. MR angiography should be performed with gadolinium. Impaired renal function prevents using gadolinium due to the association with nephrogenic systemic fibrosis.

\section{Catheter Angiography}

Because of the usefulness and ready availability of noninvasive imaging modalities, catheter angiography is rarely used now as a primary diagnostic modality but rather as a problem-solving tool. When necessary, digital subtraction angiography should be used when evaluating the aorta, iliac, and runoff vessels. ${ }^{3}$ Digital subtraction angiography is most often combined with simultaneous endovascular treatment, when appropriate. Of note, a useful diagnostic technique is carbon dioxide angiography, especially in those patients with marginal renal function or severe contrast allergy. Consideration should also be given to treatment with sodium bicarbonate in patients with marginal renal function prior to and following administration of intravenous contrast.
Trans-stenotic Pressure Measurement

In cases in which the severity of a stenosis is uncertain, trans-stenotic intra-arterial pressure measurements should be obtained. ${ }^{3}$ A peak systolic pressure gradient of $>10 \mathrm{~mm} \mathrm{Hg}$ or a $5 \mathrm{~mm} \mathrm{Hg}$ mean pressure gradient is considered significant. A 10 to $15 \mathrm{~mm} \mathrm{Hg}$ peak systolic pressure gradient after injection of intra-arterial nitroglycerine or other vasodilator to simulate exercise is also considered significant. ACC/AHA guidelines suggest that when iliac arterial stenoses of 50 to $75 \%$ are identified, significance needs to be determined with intra-arterial pressure gradient measurement prior to intervening $^{3}$ (Fig. 2).

\section{TRANSATLANTIC INTER-SOCIETY CONSENSUS GUIDELINES}

The TransAtlantic Inter-Society Consensus (TASC) guidelines, first published in 2000 and then revised in 2007, classify aortic and iliac lesions by lesion morphology. TASC A lesions include unilateral or bilateral CIA stenoses or unilateral or bilateral single short stenosis $(\leq 3 \mathrm{~cm})$ of EIA. TASC B lesions include short segment stenosis $(\leq 3 \mathrm{~cm})$ of infrarenal aorta, unilateral CIA occlusion, single or multiple stenosis totaling $3-10 \mathrm{~cm}$ involving the EIA and not extending into the common femoral artery (CFA), unilateral EIA occlusion not involving the origins of the internal iliac artery or CFA. TASC C lesions include bilateral CIA occlusions, bilateral EIA stenoses 3 to $10 \mathrm{~cm}$ long not extending into the CFA, unilateral EIA stenosis extending into the CFA, unilateral EIA occlusion that involves the origins of the internal iliac and/or CFA, heavily calcified unilateral EIA occlusion with or without internal iliac and/ or CFA origin involvement. TASC D lesions involve infrarenal aortoiliac occlusion; diffuse disease involving the aorta and both iliac arteries requiring treatment; diffuse multiple stenoses involving the unilateral CIA, EIA, and CFA; unilateral occlusions of both the CIA and EIA; bilateral occlusions of EIA; iliac stenoses in those requiring treatment for AAA who are poor candidates for endovascular treatment or who have other lesions requiring open surgical repair of aorta or iliac arteries. TASC II recommends endovascular treatment for TASC A and B lesions and surgical therapy for TASC C and D lesions. ${ }^{1}$ Several studies have reported success with endovascular treatment of TASC C and D lesions, ${ }^{8-10}$ and patient presentation and comorbidities should be taken into account when planning treatment.

\section{NONENDOVASCULAR THERAPY}

\section{Medical Therapy}

ACC/AHA guidelines suggest smoking cessation and hyperlipidemia, diabetes, and hypertension management 
A
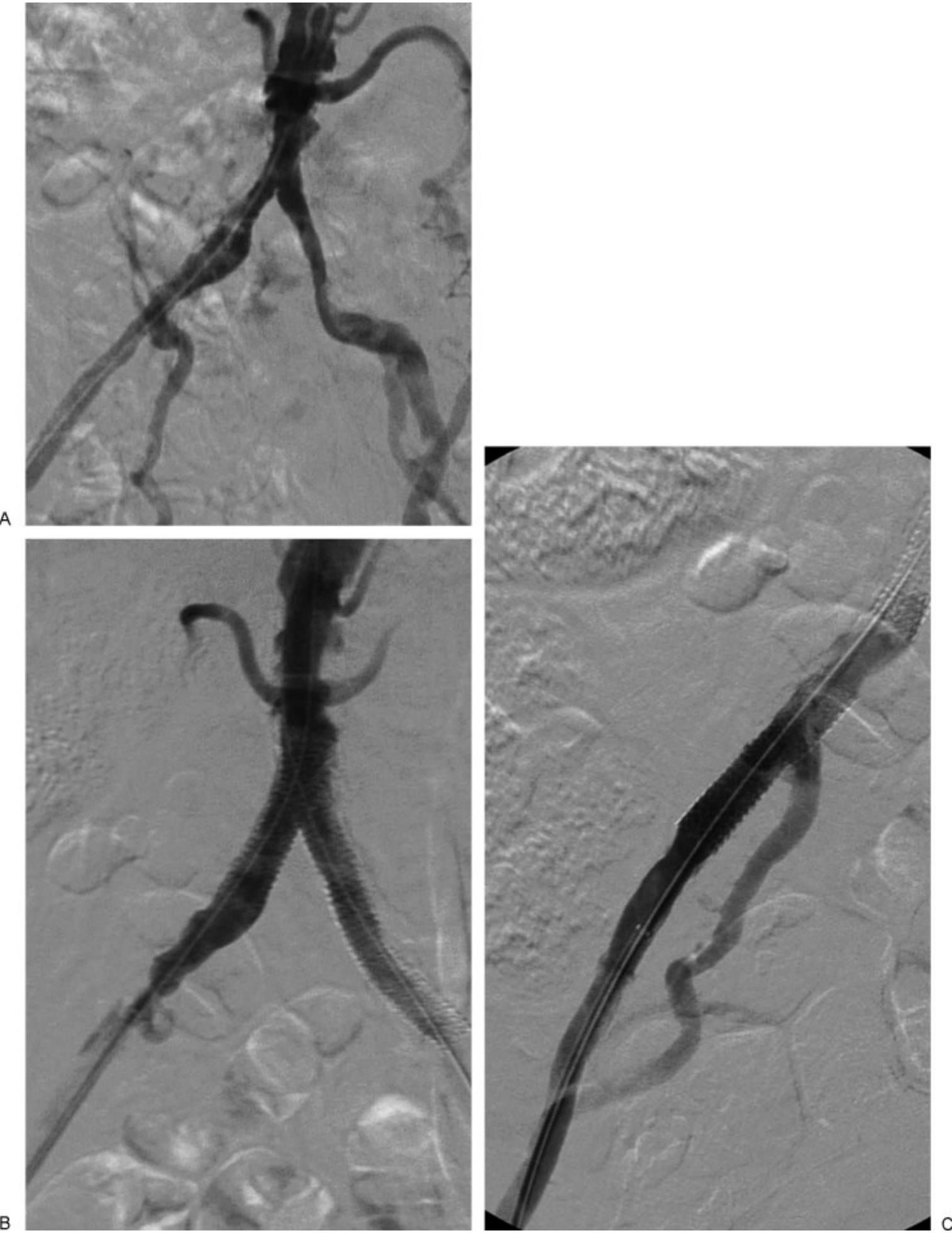

Figure 2 Trans-stenotic pressure measurement. (A) Distal abdominal aortic, bilateral common iliac artery (CIA) and right external iliac artery (EIA) stenoses. Intra-arterial pressure measurement confirms lesion significance with gradient of $18 \mathrm{~mm} \mathrm{Hg}$ at right CIA origin. (B) "Kissing" bilateral CIA primary stent deployment to treat right CIA origin stenosis and mid left $\mathrm{CIA}$ stenosis. Right CIA pressure gradient has resolved after stenting, but right EIA stenosis persists. (C) Right EIA stenosis resolved after primary stent deployment. 
as well as antiplatelet therapy according to current treatment guidelines for asymptomatic patients. ${ }^{3}$ Aspirin and other antiplatelet agents (clopidogrel) are important to reduce the risk of cardiovascular events in those with PAD, but they have not been shown to reduce claudication. ${ }^{11}$ Also to be considered is the use of angiotensinconverting enzyme inhibiting medication for cardiovascular risk reduction in asymptomatic individuals with PAD. Smoking cessation and successful management of hypertension and dyslipidemia can slow the progression of PAD. ${ }^{1}$ Supervised exercise therapy may also be effective in some, especially older male patients. ${ }^{12}$ Cilostazol has been shown to be effective in randomized controlled trials to reduce claudication. ${ }^{13}$

\section{Surgical Therapy}

TASC II suggests surgical therapy for type C and D lesions. ${ }^{1}$ Surgical options for AIOD are anatomic versus extra-anatomic bypass graft or endarterectomy. Patency of aortic bifurcation grafts have been shown to be $90 \%$ and $75 \%$ at 5 and 10 years, respectively. ${ }^{2,14}$ Extraanatomic bypass graft 5-year patency ranges from 51\% (44 to 79\%) for axillary-unifemoral bypass graft to $71 \%$ (50 to $76 \%$ ) for axillary-bifemoral bypass to $75 \%$ (55 to 92\%) for femoral-femoral crossover graft. ${ }^{1}$ Patient comorbidities should be taken into account when considering surgery.

\section{ENDOVASCULAR THERAPY}

Severe lifestyle-limiting claudication; rest pain, nonhealing ulcer, gangrene, or tissue loss; stenosis of the iliac system preventing other endovascular treatment; and decreasing renal function or hypertension in patients with renal transplant are indications for aortoiliac endovascular intervention. Contraindications include lack of symptoms, uncorrected anticoagulation, or operator inexperience with lack of appropriate surgical backup in the event of complication. Endovascular treatment options include angioplasty and/or stenting. After endovascular intervention, primary patency is defined as patency without any additional treatment. Primary assisted patency is defined as reintervention when the treated segment has not occluded, and secondary patency is defined as reintervention when the treated segment has occluded.

\section{Aortic Lesions}

As mentioned, isolated infrarenal aortic occlusive disease is rare. In an article comparing patients included in the SCVIR Transluminal Angioplasty and Revascularization (STAR) Registry with infrarenal aortic occlusive disease treated percutaneously with either angioplasty (13 patients) or angioplasty plus Palmaz stent placement
(12 patients), no significant difference was found in procedural success or major or minor complication rate. $^{15}$

\section{Iliac Lesions}

Several studies have found iliac artery angioplasty and stenting to be effective procedures. ${ }^{16-18}$ As of yet, no definitive superiority of primary stent placement versus stenting after angioplasty failure has been documented. Provisional stent placement in the iliac arteries secondary to failed angioplasty with flow-limiting dissection or persistent translesional gradient is indicated. ${ }^{3}$ Primary stenting is also effective in the common or external iliac arteries. ${ }^{3}$ The Dutch Iliac Stent Trial found that angioplasty with provisional stenting of the iliac artery for angioplasty failure yielded similar technical results and would avoid stent placement in $63 \%$ of cases of IC. ${ }^{19}$ In one study, 162 iliac artery stenoses were stented after failed angioplasty, and 141 iliac artery occlusions were stented primarily. The study found primary cumulative patency rates of $70 \pm 4 \%$ after 5 years and $65 \pm 5 \%$ after 7 years and secondary patency rates of $92 \pm 2 \%$ after 5 years and $87 \pm 4 \%$ after 9 years. ${ }^{20}$ Tetteroo et al also did not show any clinical or technical difference in outcome with primary iliac stent placement versus dilatation and stent placement. ${ }^{21}$ Stents may be balloon-expandable or self-expanding, covered or uncovered. ${ }^{22}$ Houston et al evaluated the long-term patency of "kissing" self-expanding common iliac stent placement and found a primary patency rate of $89 \%, 82 \%$, and $68 \%$ at 2,5 , and 10 years, respectively. Secondary patency rates were $93 \%, 93 \%$, and $86 \%$ at 2 , 5 , and 10 years, respectively. ${ }^{23}$ In another study, iliac recanalization and stent placement in 138 patients had a technical success of $99 \%$ and primary patency rates of $90 \%, 85 \%, 80 \%$, and $68 \%$ at $3,5,7$, and 10 years, respectively. ${ }^{17}$ Figure 3 demonstrates bilateral CIA occlusions treated with primary stent deployment. Other studies have found a 5-year patency of 70 to $80 \%$ for primary stenting of the CIA. ${ }^{20,24}$ A "reentry device" may be used with success to open an iliac artery occlusion. ${ }^{25}$ Brachial access can also be considered in the event of unfavorable anatomy, such as in the setting of prior kissing iliac artery stent deployment or abdominal aortic stent-graft placement.

\section{COMBINED SURGICAL AND ENDOVASCULAR THERAPY}

CFA endarterectomy with ipsilateral iliac artery stenting or stent grafting demonstrated primary, primary assisted, and secondary patency rates of $60 \%, 97 \%$, and $98 \%$, respectively. Improved primary patency was seen when combining endarterectomy with covered stent grafts $(87 \%)$ versus bare stents $(53 \%) .^{26}$ 
A
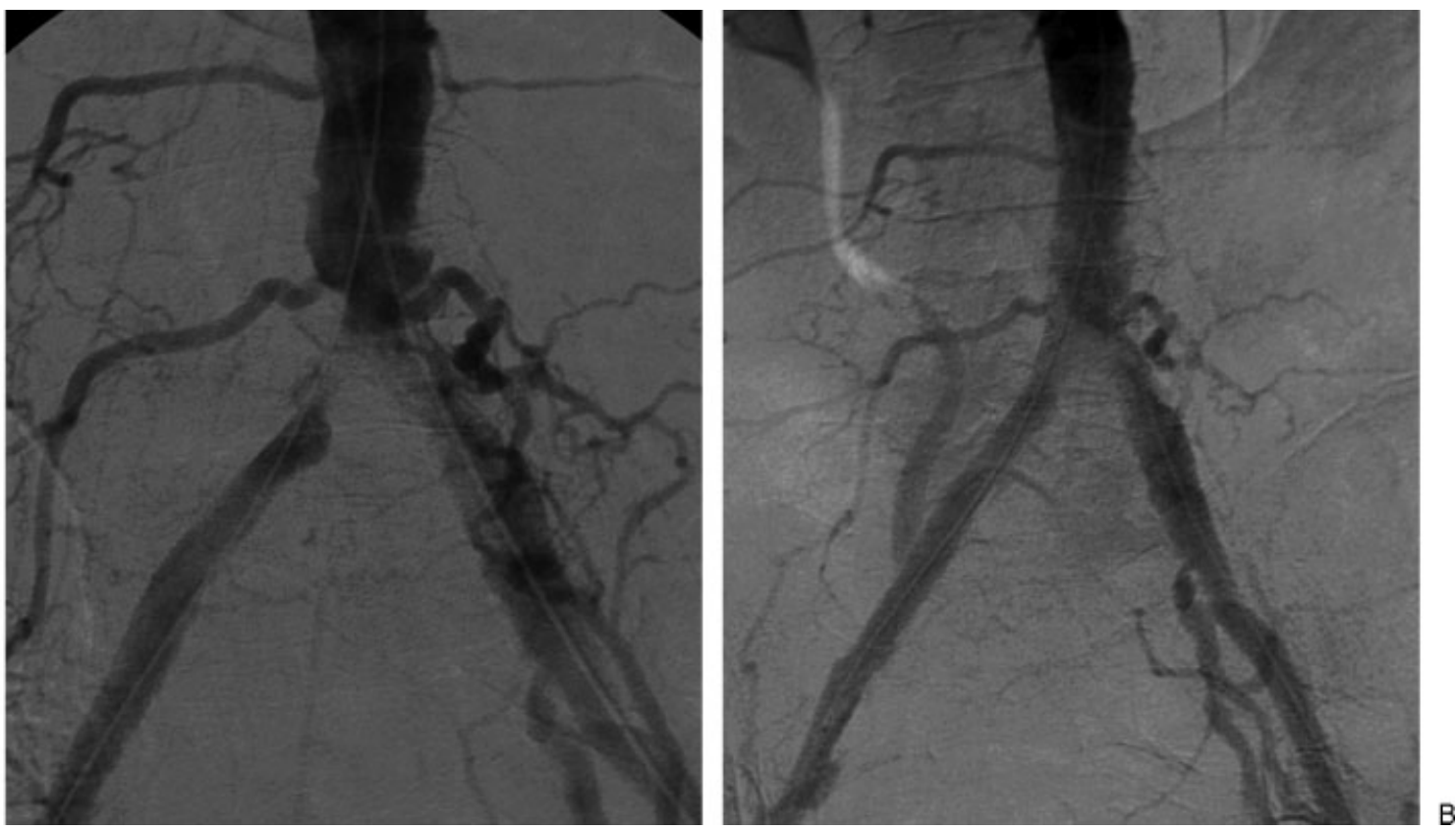

Figure 3 Recanalization of bilateral common iliac artery (CIA) occlusions. (A) Chronic total occlusion of bilateral CIAs with wire recanalization via bilateral common femoral arteries. (B) Successful primary CIA stent deployment.

\section{COMPLICATIONS OF ENDOVASCULAR THERAPY}

Many studies have shown that both angioplasty and stenting of infrarenal abdominal aortic stenoses are safe treatments. ${ }^{27-33}$ One case report cites an arterioureteric fistula formation after EIA angioplasty and stenting. ${ }^{34}$ Immediate complications include thrombosis, distal embolization, pseudoaneurysm, and arterial rupture. Most complications involve the access site. Often, careful attention to choice of appropriate puncture site and adequate hemostasis at procedure completion can prevent access site complications. Long-term complications include stent fracture, intimal hyperplasia, and thrombosis.

\section{ADJUNCTIVE THERAPY}

Antiplatelet therapy with aspirin or clopidogrel may prevent formation of thrombus within stented arteries. ${ }^{20,35}$ TASC II guidelines recommend initiation of antiplatelet therapy at the time of endovascular intervention and continuation indefinitely. ${ }^{1}$

\section{SURVEILLANCE}

The first clinical follow-up after an endovascular intervention includes evaluation of the arterial puncture site for complication as well as vascular ultrasound and $\mathrm{ABI}$ calculation to establish the new baseline. Although ultrasound surveillance schedules vary, a plausible schedule is at 1 month after intervention, at 6 months, and then yearly and as needed. Presence or absence of symptoms should be documented in the ultrasound report.

\section{CONCLUSION}

The high prevalence of AIOD and potential for severe lifestyle-limiting claudication and/or tissue loss necessitates appropriate evaluation and management of this disease. With a combination of medical management of modifiable risk factors for $\mathrm{PAD}$, accurate noninvasive and/or invasive diagnostic evaluation for patients with claudication or CLI, and endovascular and/or surgical revascularization when appropriate, symptomatic aortoiliac disease is often improved.

\section{REFERENCES}

1. Norgren L, Hiatt WR, Dormandy JA, et al. Inter-Society Consensus for the Management of Peripheral Arterial Disease (TASC II). J Vasc Surg 2007;45(Suppl S):S5-S67

2. Brewster DC. Clinical and anatomical considerations for surgery in aortoiliac disease and results of surgical treatment. Circulation 1991;83(2 Suppl):I42-I52

3. Hirsch AT, Haskal ZJ, Hertzer NR, et al; American Association for Vascular Surgery/Society for Vascular Surgery; Society for Cardiovascular Angiography and Interventions; Society for Vascular Medicine and Biology; Society of Interventional Radiology; ACC/AHA Task Force on Practice Guidelines. ACC/AHA Guidelines for the Management of Patients with Peripheral Arterial Disease (lower extremity, renal, mesenteric, and abdominal aortic): a collaborative report from the American Associations for Vascular Surgery/Society for Vascular Surgery, Society for Cardiovascular Angiography and Interventions, Society for Vascular Medicine and Biology, Society of Interventional Radiology, and the ACC/AHA Task Force on Practice Guidelines (writing committee to develop guidelines for the management of patients with peripheral arterial disease)—summary of recommendations. J Vasc Interv Radiol 2006;17:1383-1397; quiz 1398 
4. Widmer L, Biland L. Risk profile and occlusive peripheral arterial disease. Proceedings of 13th International Congress of Angiology; J Cardiovasc Nurs 1985:28

5. Kannel WB, Skinner JJ Jr, Schwartz MJ, Shurtleff D. Intermittent claudication. Incidence in the Framingham Study. Circulation 1970;41:875-883

6. Criqui MH, Vargas V, Denenberg JO, et al. Ethnicity and peripheral arterial disease: the San Diego Population Study. Circulation 2005;112:2703-2707

7. Bertino RE, Grassi CJ, Bluth EI, et al; American College of Radiology, American Institute of Ultrasound in Medicine, Society of Interventional Radiology. Practice guideline for the performance of physiologic evaluation of extremity arteries. J Vasc Interv Radiol 2007;18:1203-1206

8. Balzer JO, Gastinger V, Ritter R, et al. Percutaneous interventional reconstruction of the iliac arteries: primary and long-term success rate in selected TASC C and D lesions. Eur Radiol 2006;16:124-131

9. Leville CD, Kashyap VS, Clair DG, et al. Endovascular management of iliac artery occlusions: extending treatment to TransAtlantic Inter-Society Consensus class $\mathrm{C}$ and $\mathrm{D}$ patients. J Vasc Surg 2006;43:32-39

10. Sixt S, Alawied AK, Rastan A, et al. Acute and long-term outcome of endovascular therapy for aortoiliac occlusive lesions stratified according to the TASC classification: a single-center experience. J Endovasc Ther 2008;15:408416

11. Cosmi B, Conti E, Coccheri S. Anticoagulants (heparin, low molecular weight heparin and oral anticoagulants) for intermittent claudication. Cochrane Database Syst Rev 2001;(3):CD001999

12. Lowensteyn I, Coupal L, Zowall H, Grover SA. The costeffectiveness of exercise training for the primary and secondary prevention of cardiovascular disease. J Cardiopulm Rehabil 2000;20:147-155

13. Regensteiner JG, Ware JE Jr, McCarthy WJ, et al. Effect of cilostazol on treadmill walking, community-based walking ability, and health-related quality of life in patients with intermittent claudication due to peripheral arterial disease: meta-analysis of six randomized controlled trials. J Am Geriatr Soc 2002;50:1939-1946

14. de Vries SO, Hunink MG. Results of aortic bifurcation grafts for aortoiliac occlusive disease: a meta-analysis. J Vasc Surg 1997;26:558-569

15. Westcott MA, Bonn J. Comparison of conventional angioplasty with the Palmaz stent in the treatment of abdominal aortic stenoses from the STAR registry. SCVIR Transluminal Angioplasty and Revascularization. J Vasc Interv Radiol 1998;9:225-231

16. Carnevale FC, De Blas M, Merino S, et al. Percutaneous endovascular treatment of chronic iliac artery occlusion. Cardiovasc Intervent Radiol 2004;27:447-452

17. Gandini R, Fabiano S, Chiocchi M, Chiappa R, Simonetti G. Percutaneous treatment in iliac artery occlusion: long-term results. Cardiovasc Intervent Radiol 2008;31:1069-1076

18. Tsetis D, Uberoi R. Quality improvement guidelines for endovascular treatment of iliac artery occlusive disease. Cardiovasc Intervent Radiol 2008;31:238-245

19. Tetteroo E, Haaring C, van der Graaf $Y$, van Schaik JP, van Engelen AD, Mali W; PDutch Iliac Stent Trial Study
Group. Intraarterial pressure gradients after randomized angioplasty or stenting of iliac artery lesions. Cardiovasc Intervent Radiol 1996;19:411-417

20. Reyes R, Carreira JM, Gude F, et al. Long-term follow-up of iliac wallstents. Cardiovasc Intervent Radiol 2004;27: 624-631

21. Tetteroo E, van der Graaf Y, Bosch JL, et al; Dutch Iliac Stent Trial Study Group. Randomised comparison of primary stent placement versus primary angioplasty followed by selective stent placement in patients with iliac-artery occlusive disease. Lancet 1998;351:1153-1159

22. Leung DA, Spinosa DJ, Hagspiel KD, Angle JF, Matsumoto AH. Selection of stents for treating iliac arterial occlusive disease. J Vasc Interv Radiol 2003;14(2 Pt 1):137-152

23. Houston JG, Bhat R, Ross R, Stonebridge PA. Long-term results after placement of aortic bifurcation self-expanding stents: 10 year mortality, stent restenosis, and distal disease progression. Cardiovasc Intervent Radiol 2007;30:42-47

24. Bosch JL, Hunink MG. Meta-analysis of the results of percutaneous transluminal angioplasty and stent placement for aortoiliac occlusive disease. Radiology 1997;204:87-96

25. Ramjas G, Thurley P, Habib S. The use of a re-entry catheter in recanalization of chronic inflow occlusions of the common iliac artery. Cardiovasc Intervent Radiol 2008;31:650-654

26. Chang RW, Goodney PP, Baek JH, Nolan BW, Rzucidlo EM, Powell RJ. Long-term results of combined common femoral endarterectomy and iliac stenting/stent grafting for occlusive disease. J Vasc Surg 2008;48:362-367

27. Morag B, Garniek A, Bass A, Schneiderman J, Walden R, Rubinstein ZJ. Percutaneous transluminal aortic angioplasty: early and late results. Cardiovasc Intervent Radiol 1993;16: $37-42$

28. Ravimandalam K, Rao VRK, Kumar S, et al. Obstruction of the infrarenal portion of the abdominal aorta: results of treatment with balloon angioplasty. AJR Am J Roentgenol 1991;156:1257-1260

29. Diethrich EB, Santiago O, Gustafson G, et al. Preliminary observations on the use of the Palmaz stent in the distal portion of the abdominal aorta. Am Heart J 1993;125(2 pt 1): 490-501

30. Long AL, Gaux JC, Raynaud AC, et al. Infrarenal aortic stents: initial clinical experience and angiographic follow-up. Cardiovasc Intervent Radiol 1993;16:203-208

31. Vorwerk D, Günther RW, Schürmann K, Wendt G. Aortic and iliac stenoses: follow-up results of stent placement after insufficient balloon angioplasty in 118 cases. Radiology 1996; 198:45-48

32. Yakes WF, Kumpe DA, Brown SB, et al. Percutaneous transluminal aortic angioplasty: techniques and results. Radiology 1989;172(3 Pt 2):965-970

33. Charlebois N, Saint-Georges GS, Hudon G. Percutaneous transluminal angioplasty of the lower abdominal aorta. AJR Am J Roentgenol 1986;146:369-371

34. Aarvold A, Wales L, Papadakos N, Munneke G, Loftus I, Thompson M. Arterio-ureteric fistula following iliac angioplasty. Cardiovasc Intervent Radiol 2008;31:821-823

35. Stoeckelhuber BM, Szeimies U, Spengel FA, Kueffer G. Late thromboembolic complication from a Palmaz stent in the common iliac artery. Cardiovasc Intervent Radiol 1996; 19:190-192 